\title{
Design of header and coil steam generators for concentrating solar power applications accounting for low-cycle fatigue requirements
}

\author{
Ferruzza, Davide; Kærn, Martin Ryhl; Haglind, Fredrik
}

Published in:

Applied Energy

Link to article, DOI:

10.1016/j.apenergy.2018.12.030

Publication date:

2019

Document Version

Peer reviewed version

Link back to DTU Orbit

Citation (APA):

Ferruzza, D., Kærn, M. R., \& Haglind, F. (2019). Design of header and coil steam generators for concentrating solar power applications accounting for low-cycle fatigue requirements. Applied Energy, 236, 793-803.

https://doi.org/10.1016/j.apenergy.2018.12.030

\section{General rights}

Copyright and moral rights for the publications made accessible in the public portal are retained by the authors and/or other copyright owners and it is a condition of accessing publications that users recognise and abide by the legal requirements associated with these rights.

- Users may download and print one copy of any publication from the public portal for the purpose of private study or research.

- You may not further distribute the material or use it for any profit-making activity or commercial gain

- You may freely distribute the URL identifying the publication in the public portal 


\title{
Design of header and coil steam generators for concentrating solar power applications accounting for low-cycle fatigue requirements
}

\author{
Davide Ferruzza $^{\mathrm{a}}$, Martin Ryhl Kærn ${ }^{\mathrm{a}}$, Fredrik Haglind ${ }^{\mathrm{a}}$ \\ ${ }^{a}$ Department of Mechanical Engineering, Technical University of Denmark, 2800 Kongens Lyngby, \\ Denmark
}

\begin{abstract}
Concentrating solar power plants are experiencing an increasing share in the renewable energy generation market. Among them, parabolic trough plants are the most commercially mature technology. These plants still experience many challenges, one of which is the cyclic daily start-up and shut down procedures. These pose new challenges to industrially mature components like the steam generator system, as frequent load changes might decrease their lifetime considerably due to cyclic thermo-mechanical stress loads. In this context, the header and coil design is a promising configuration to minimize the stresses.

This paper presents a method to design the header and coil heat exchangers of the steam generator, considering low-cycle fatigue requirements, by defining minimum allowable heating rates for the evaporator and superheater. Optimal designs were obtained by minimizing the total water pressure drops and purchase equipment costs. A comparison with a sizing routine without accounting for low-cycle fatigue constraints was also conducted.

The model was validated against the component data of a 55 MWe power plant, with a maximum deviation on the total area estimation of $+2.5 \%$. The results suggest that including the heating rate constraints in the design routine affects sensibly the optimal design configuration, with a $41 \%$ cost increase for a 1 bar pressure drop. Tube outer diameters of $38 \mathrm{~mm}$ and $50 \mathrm{~mm}$ and low number of tubes per layer (4-10) for the superheater represent the optimal design to maximize the lifetime of the components.
\end{abstract}

Keywords: Concentrating solar power, Parabolic trough power plants, Steam generator, Heat exchanger design, Heating rates

\section{Nomenclature}

\section{Abbreviations}

BPVC boiler pressure vessel code 
CSP concentrating solar power

D deaerator

ECO economizer

EVA evaporator

HP high pressure

HPI historical price index

HTRI Heat Transfer Research, Inc.

LP low pressure

PTPP parabolic trough power plant

RH re-heater

SGS steam generator system

SH superheater

ST steam Turbine

TEMA tubular exchangers manufacturers association

\section{Subscripts}

b bend

dc downcomer

dp driving pressure

e parallel to the economizer

fm friction and momentum

hx heat exchanger

i inside

m mechanical 
o outside

r riser

s parallel to the super-heater

s shell

$\mathrm{T}$ thermal

tl tube layer

txl tube for each layer

\section{Symbols}

$\alpha \quad$ stress concentration factor,

$\beta \quad$ thermal expansion coefficient,

$\lambda \quad$ thermal conductivity,

$\nu \quad$ Poisson ratio,

$\omega \quad$ outer to inner diameter ratio,

$\Phi_{\mathrm{w}}$ non-dimensional geometrical coefficient,

$\rho$ density,

$\sigma \quad$ stress,

$\theta \quad$ tube coil angle of bend,

$f \quad$ heat exchanger specific cost front head correction factor,

$f_{\mathrm{D}} \quad$ darcy's friction factor,

$p_{\mathrm{OD}}$ heat exchanger specific cost outer diameter correction factor,

$r \quad$ heat exchanger specific cost rear head correction factor,

$S_{\mathrm{l}} \quad$ longitudinal pitch,

$S_{\mathrm{t}} \quad$ transversal pitch, 
$v_{\mathrm{T}} \quad$ heating rate,

A area,

b heat exchanger specific cost,

c heat exchanger specific cost correction factor,

E Young's modulus,

F LMTD correction factor,

h heat transfer coefficient,

ID internal diameter,

L length,

OD outer diameter,

p pressure,

PEC purchasement equipment cost,

S maximum allowable stress,

T temperature,

t thickness,

U overall heat transfer coefficient,

u velocity,

y safety coefficient,

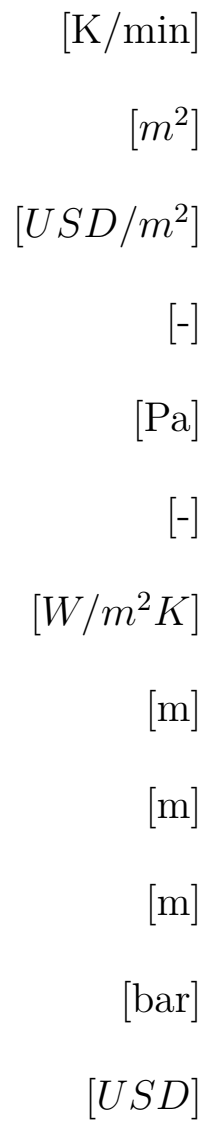

$[\mathrm{K} / \mathrm{min}]$

$\left[m^{2}\right]$

$\left[U S D / m^{2}\right]$

$[-]$

$[\mathrm{Pa}]$

$[-]$

$\left[W / m^{2} K\right]$

$[\mathrm{m}]$

[m]

[m]

[bar]

[USD]

[Pa]

$\left[{ }^{\circ} \mathrm{C}\right]$

[m]

$\left[W / m^{2} K\right]$

$[\mathrm{m} / \mathrm{s}]$

[-] 


\section{Introduction}

Today's growing attention towards renewable energy sources is posing an increasing demand for flexibility towards electricity generation. Concentrating solar power (CSP) plants are experiencing a developing interest in this context. Specifically, the possibility to integrate such technology with relatively cheap ways of storing thermal energy allows them to decouple the electricity output from the solar input, making them suitable for alternating electricity grid loads [1]. Even though an interesting technology, CSP plants are still not fully competitive with respect to fossil-fuel based technologies. From a technical perspective, the fluctuating and stochastic nature of solar radiation causes operating challenges such as frequent variations in load and daily start-up and shut-down procedures. A way to overcome these challenges is to improve the operating performance by maximizing the flexibility of the components towards fluctuating loads. By doing so it is possible to utilize solar irradiation as effectively as possible, therefore maximizing the electrical energy production and profitability [2]. On the other hand, in order to preserve the lifetime of certain components, the maximum gradient of temperature (heating rate) is limited by thermo-mechanical constraints.

Parabolic trough power plants (PTPP) represent the most technically and economically mature technology among CSP plants. They account for around $80 \%$ of both the currently installed and planned to be constructed power plants [3-5]. In such power plants, the conventional fossil fuel fired boiler is replaced by a series of parabolic mirrors lenses to concentrate direct beam solar radiation onto the receiver tubes to produce useful high temperature heat. This can be used to produce electricity by a Rankine cycles. The main link between the solar field and the power block is the steam generator system (SGS). It consists of a train of heat exchangers which transfer the useful high temperature heat from a heat transfer fluid (HTF) to the water coming from the condensing line of the Rankine cycle. The temperature of the liquid water is raised until reaching superheated steam conditions at the inlet of the turbine [4].

Generally the SGS, together with the steam turbines, poses limitations with regards to the rate of the power block start-up [6]. High temperature gradients induce high thermal stresses and therefore limit the lifetime of such components. Specifically the maximum heating rates at which the SGS can experience a temperature increase is limited by the thermo-mechanical stresses on the thick-walled components and junctions such as the steam drum, super-heater headers and $\mathrm{T}$ or $\mathrm{Y}$ junctions in the steam pipelines [7-9]. The main limiting component is usually the evaporator steam drum, which is designed as a high 
pressure vessel with a large diameter, hence consisting of thick walls. Regarding the most conventional single phase heat exchangers, the heating rates are limited by the stresses in the thick tube plates [10]. The maximum heating rates are calculated based on low cycle fatigue (LCF) theories, by minimizing the resulting stress from a cyclic load and keeping it below a safety treshold to guarantee the required lifetime [11]. It is of common practice in the industry to do so by using the European norm EN 12952-3, which illustrates all the steps to calculate minimum and maximum allowable heating rates [12].

Many CSP plants currently in operation, have SGSs which were designed as conventional heat exchangers, not optimized for transient operation [13]. One of the possible configuration that can be used to overcome such problems is the header and coil design. In contrast to what happens in kettle reboiler type evaporators or TEMA (Tubular exchangers manufacturers association) heat exchangers, the coil type heat exchanger does not have thick tube plates. The heat transfer fluid (HTF) flows are distributed to the tube bank via a circular manifold (header). The round shape of the header results in lower thickness requirements for pressure resistance, therefore low thermal stresses which are proportional to the square of the thickness [14]. A similar reasoning can be applied to the single phase heat exchangers, such as the economizer (ECO), re-heaters $(\mathrm{RH})$ and superheaters $(\mathrm{SH})$. Also in this case the typical TEMA F or $\mathrm{H}$ heat exchangers are characterized by thick tube plates which reduce their transient response.

The design of the heat exchangers used in the energy system is characterized by two steps, the heat transfer area estimation and pressure drop calculations coupled with a cost analysis. One of the most common methods to size the shell and tube heat exchangers is the Delaware method for shell side calculations, which takes into account the different fluid flow paths in the complex shell geometry [15]. Another available method in literature is the Stream Analysis method, which is also implemented in the commercially available software HTRI (Heat Transfer Research, Inc.) [16]. However, if the shell geometry is not too complex, the method proposed by Kern [17] can be used to obtain a good approximation of the area requirements. Considering tube banks, the method summarized by Anarratore et al. $[18,19]$ can be applied to modify the logaritmic mean temperature based on the tube configurations. Regarding the cost estimation, both simplified [20] and more detailed methods are available. Concerning the latter, Purohit [21] proposed a method to estimate the cost of the heat exchangers not only based on the area requirements but also on many other factors such as operating pressure, tube configuration and shell sizes.

In literature, different sizing methodologies are applied to different cases. For instance 
Duran et al. [22] applied a genetic algorithm to optimize the geometric design of heat recovery steam generators (HRSG). However the focus was only on the geometrical design and not on the economic analysis. A similar approach is presented by Franco et al. [23], and in this case a two step optimization approach is presented, by firstly minimizing pressure drops and secondly minimizing the dimension of the heat exchangers. As for the associated cost, for instance, Wildi-Tremblay and Gosselin [24] used a genetic algorithm to minimize both investment and operational costs. Gonzalez-Gomez et al. [25] applied a cost-based optimization methodology to find a trade-off between levelized cost of electricity and investment costs for the SGS specifically for parabolic trough power plant applications.

In general, it can be said that many design methodologies are available and applied in literature, but none so far have taken into consideration the LCF limitations during the design phase. This is usually done as a performance check afterwards by calculating what is the maximum allowable heating rate for a specific given design. For instance Pelagotti et al. [14] analyzed the lifetime of the header and coil steam generator for a given design. A more detailed approach was performed by Gonzalez-Gomez et al. [10] who estimated the lifetime of the heat exchangers according to the ASME boiler pressure vessel code (BPVC) div. II for a given geometry and assumed heating rates. However, as concluded in a previous work by the authors [6], it is essential to include the heating rates in the design procedure. Increasing the evaporator heating rates from $3 \mathrm{~K} / \mathrm{min}$ to $7-10 \mathrm{~K} / \mathrm{min}$ could lead to an increase in the electricity production between $1.5 \%$ and $5 \%$ for a peak-load case.

The objective of this paper is to present a method to design the SGS accounting for LCF constraints for concentrating solar power applications. The significance of the results is demonstrated by comparing the results with those of a design which was obtained without considering the LCF constraints.

The thermodynamic and economic calculations were coupled in a multi-objective optimization framework aiming at minimizing both pressure drops and purchase equipment costs (PEC) considering LCF constraints as obtained from Ref. [6]. The header and coil design was chosen as it is a promising solution for CSP applications. The numerical models were validated with data provided by a manufacturer of a 55 MWe PTPP without storage.

In section 2 , the paper presents the methods used to calculate the required heat transfer parameters and pressure drops as well as the cost estimation and LCF heating rates calculations. Furthermore it presents the multi-objective optimization method and required constraints to obtain feasible solutions. Section 3 presents and discusses the results of the validation and multi-objective optimization performed for two different cases to compare the 
results with the ones obtained without accounting for LCF constraints. Section 4 outlines the conclusions and final remarks. 


\section{Methods}

Figure 1 illustrates the main steps that are required for the design routine. The grey and black boxes represent the inputs and outputs of the model, respectively.

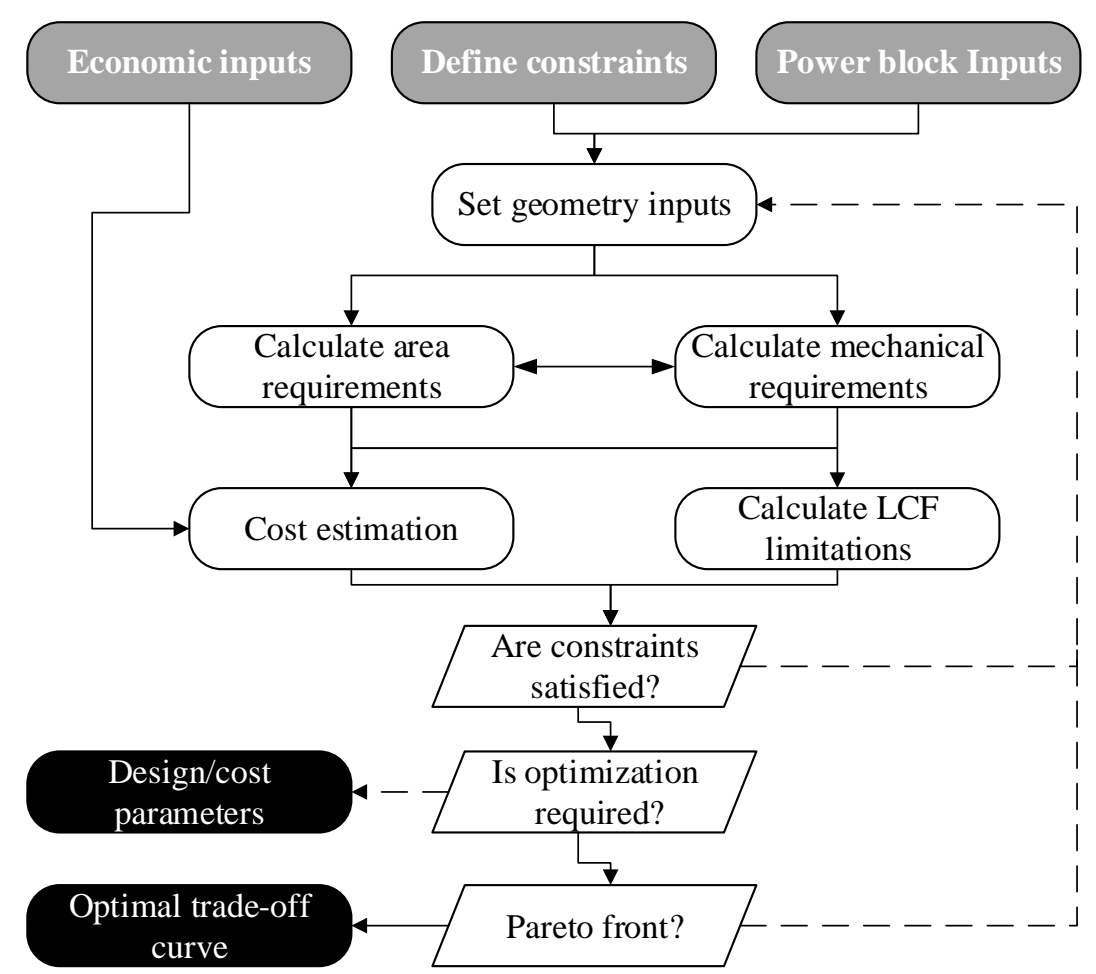

Figure 1: SGS design method workflow.Solid lines represent a YES logic while dashed lines represent a NO logic.

In order to perform the SGS design, power block data and operating constraints are the required inputs together with price data if economic calculations are done. The results of the design serve for the LCF analysis according to the norm EN12952-3 [12]. If the constraints are not met, the geometry inputs are changed until the requirements are satisfied.

The model can be coupled with a multi-objective optimizer available in the matlab toolbox [26]. At the start of the optimization, it is possible to set conflicting objectives with regards to whether to maximize or minimize their quantities. Both design parameters and operation parameters can be set to allow for variations within the limits chosen for the study. The algorithm performs then as many iterations as needed to finalize the optimization and obtain an optimal trade-off curve or Pareto front [27]. 


\subsection{Case study}

The power plant of the case study is based on a PTPP similar to the Andasol 1, located near Sevilla [28]. The main difference is the absence of the thermal energy storage and the arrangement of the re-heaters, as in this case the $\mathrm{RH}$ is split into two heat exchangers parallel to the economizer (RHe) and the superheater (RHs). The two-fold split of the reheater allows for lower temperature gradients on the tubes, thus resulting in lower thermal stresses [29]. Figure 2 illustrates a diagram of the reference power plant and the arrangement of the heat exchangers in the system.

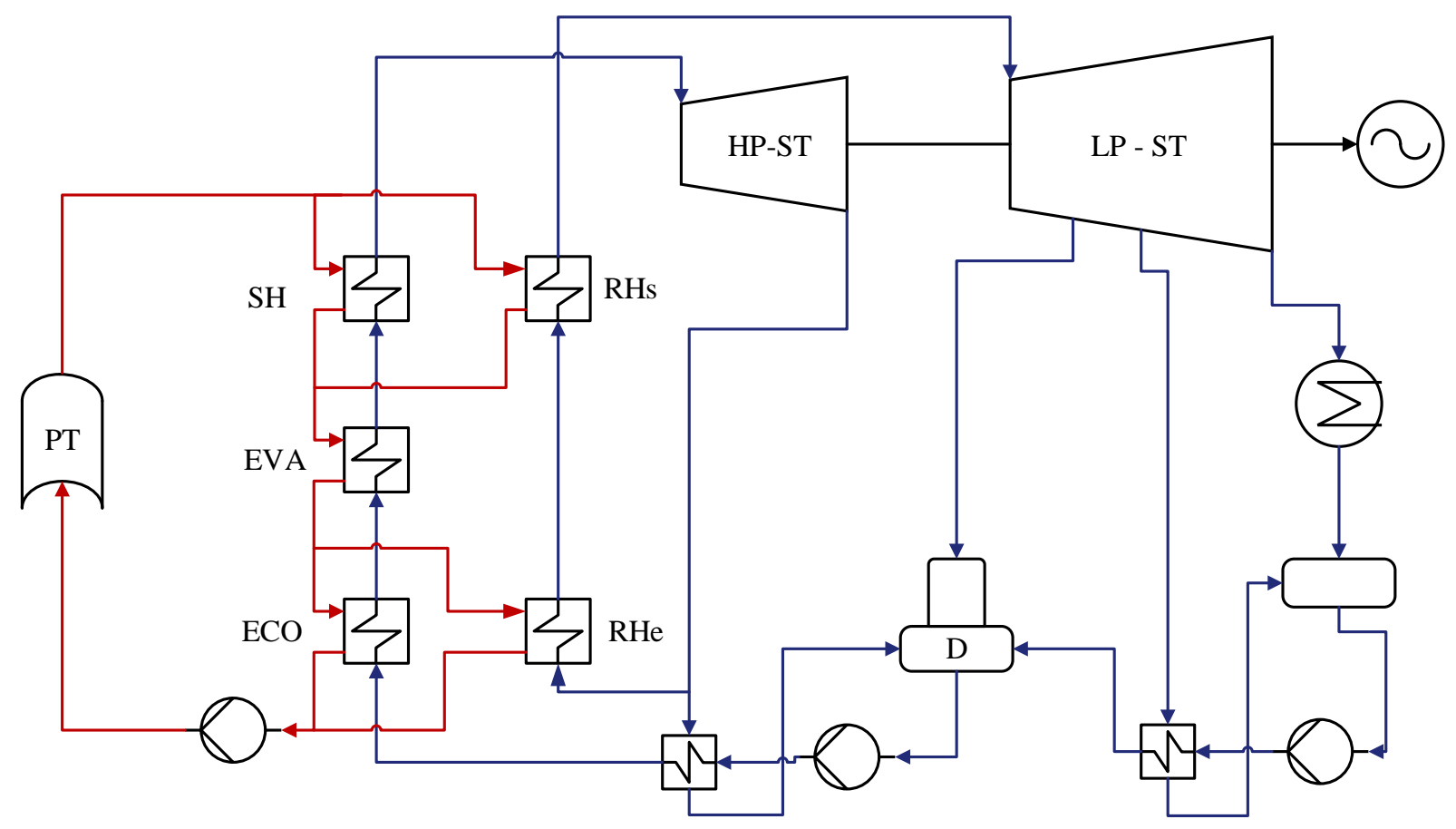

Figure 2: Parabolic trough power plant layout

The red lines represent the HTF (Terminol-VP1) loop, which is heated up by the parabolic trough (PT) mirrors and fed directly to the steam generator system. The blue line cycle represents a regenerative Rankine-reheat cycle with high pressure (HP) and low pressure (LP) steam turbines (ST), a condenser and a deaerator (D). The main inputs required for defining the boundary condition of the SGS are summarized in Table 1.

The SGS consists of two parallel trains which comprise a SH, ECO, EVA and two RHs [25]. The heat transfer fluid flows on the shell-side in the single phase heat exchangers. In the evaporator the heat transfer fluid flows in the tube-side, while the heat transfer is characterized by pool boiling on the shell-side. The water flows in the tubes for all the other 
Table 1: Power block boundary conditions

\begin{tabular}{llr}
\hline Parameters & Units & Value \\
\hline Turbine Inlet Temperature & {$\left[{ }^{\circ} \mathrm{C}\right]$} & 385.34 \\
Turbine Inlet Pressure & {$[\mathrm{bar}]$} & 104 \\
Reheat Outlet Temperature & {$\left[{ }^{\circ} \mathrm{C}\right]$} & 386.46 \\
Inlet pressure at Reheat & {$[\mathrm{bar}]$} & 20.25 \\
Inlet temperature at Reheat & {$\left[{ }^{\circ} \mathrm{C}\right]$} & 213 \\
Feedwater temperature & {$\left[{ }^{\circ} \mathrm{C}\right]$} & 256.8 \\
HTF inlet temperature & {$\left[{ }^{\circ} \mathrm{C}\right]$} & 393.3 \\
HTF inlet pressure & {$[\mathrm{bar}]$} & 15 \\
Heat load requirement & {$[\mathrm{MW}]$} & 166.2 \\
\hline
\end{tabular}

heat exchangers. The blue and red lines represent respectively the water and heat transfer fluid flows. The HTF flows through the SGS to supply the thermal energy to increase the temperature of the inlet subcooled water to the desired turbine inlet temperature. The low pressure steam, coming from the extraction, is heated up in the two re-heaters to the desired re-heat turbine inlet temperature.

To both reduce the dimensions of the HTF header and the EVA shell, the heat exchanger was split in two. The EVA is characterized by a natural circulation arrangement between the steam drum and the heat exchangers. Figure 3 illustrates the geometrical configuration of the evaporator under consideration, while Figure 4 shows the single phase heat exchangers geometry, which was approximated as parallel tube banks as illustrated in Figure 5, where $S_{\mathrm{l}}, S_{\mathrm{t}}, N_{\mathrm{tl}}$ represent the tube longitudinal and transversal pitch and the number of tube layers, respectively.

\subsection{Heat transfer and pressure drops in the heat exchangers}

Once the the heat duty of the heat exchangers and their boundary conditions are obtained, the mean logarithmic temperature difference (LMTD) is calculated according to Equation 1 and depends on the inlet (i) and outlet (o) temperature ( $T$ ) of the cold and hot streams. $F$ is a correction factor which depends on the flow configuration. Anarratore et al. [19] suggested however that if the number of tube coils is higher than 6 , the flow configuration can be assumed to be a counter-current, therefore $F$ becomes 1 . The area $(A)$, defined in Equation 3, is calculated by using the overall heat transfer coefficient $(U)$ as defined in Equation 2. 

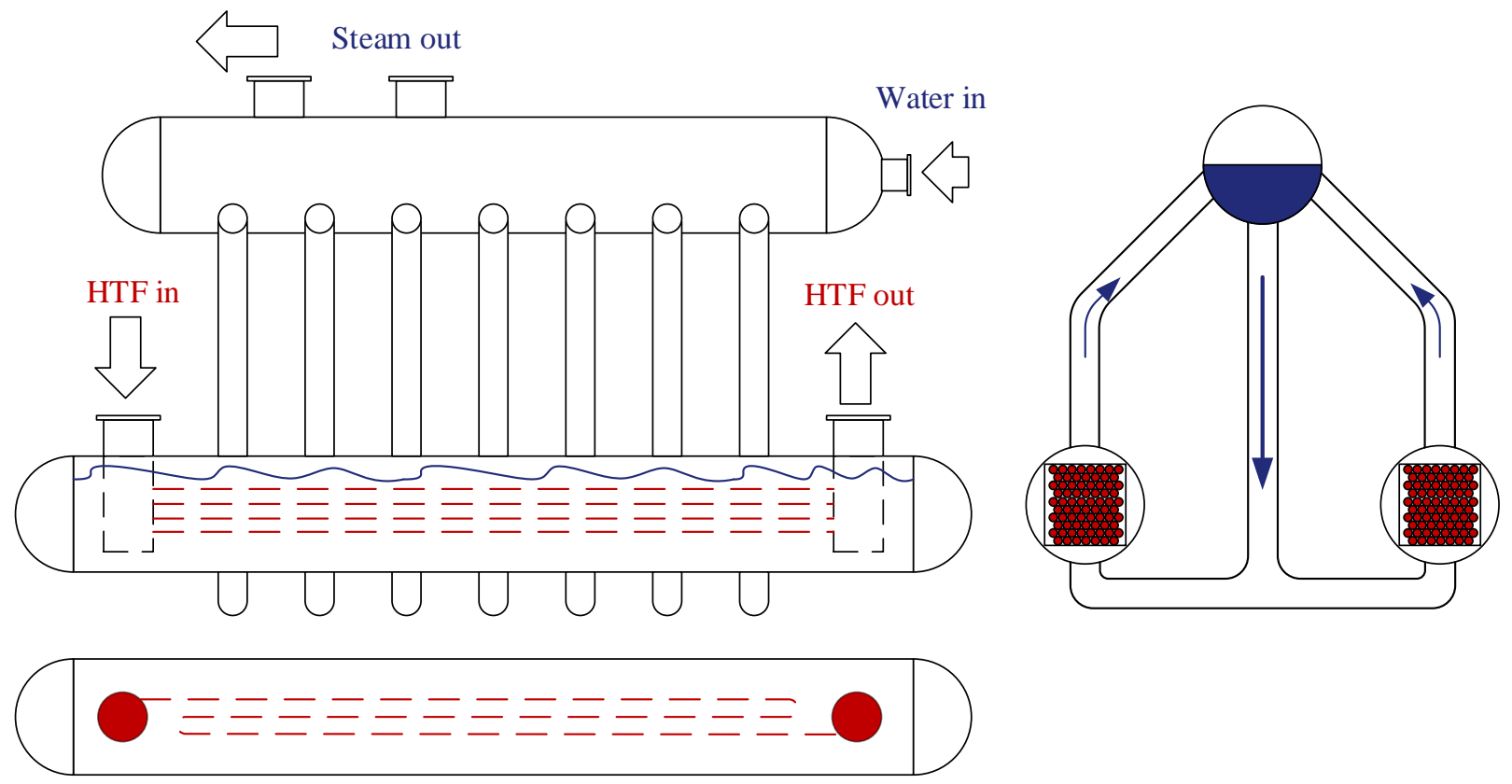

Figure 3: Header and coil shell recirculation evaporator

$$
\begin{gathered}
\Delta T_{\mathrm{LMTD}}=F \cdot \frac{\left(T_{\mathrm{i} \text {,hot }}-T_{\mathrm{o}, \text { cold }}\right)-\left(T_{\mathrm{i}, \mathrm{hot}}-T_{\mathrm{o}, \text { cold }}\right)}{\left(\ln \left(\left(T_{\mathrm{i}, \mathrm{hot}}-T_{\mathrm{o}, \text { cold }}\right) /\left(T_{\mathrm{i}, \mathrm{hot}}-T_{\mathrm{o}, \text { cold }}\right)\right)\right)} \\
Q=U \cdot A \cdot \Delta T_{\mathrm{LMTD}} \\
A_{o}=N_{\mathrm{tl}} \cdot N_{\mathrm{txl}}\left(p i \cdot \mathrm{OD} \cdot L_{\text {tube }}\right) \\
\frac{1}{U_{\mathrm{o}}}=\frac{r_{\mathrm{o}}}{r_{\mathrm{i}} \cdot h_{\mathrm{i}}}+\frac{1}{h_{\mathrm{o}}}+\frac{r_{\mathrm{o}} \cdot \ln \left(\frac{r_{\mathrm{o}}}{r_{\mathrm{i}}}\right)}{\lambda_{\mathrm{w}}}
\end{gathered}
$$

The area depends on the number of tubes for each layer (txl) and tube layers, as well as on the single tube lenght $(L)$. The $U$ value, as expressed in equation 4 , depends on the heat transfer coefficients $h$ of both shell and tube sides, the internal and outer radius $(r)$, as well as on the thermal resistance posed by the tubes which depends on the wall $(\mathrm{w})$ 


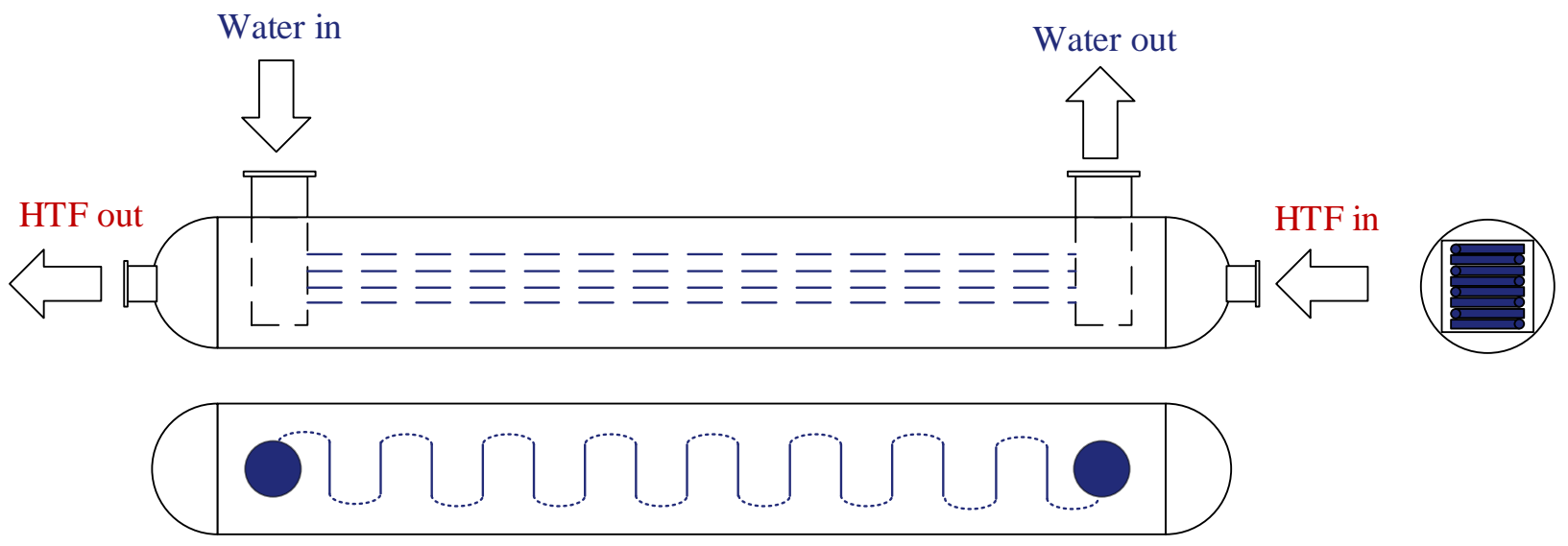

Figure 4: Header and coil shell single phase heat exchangers geometry

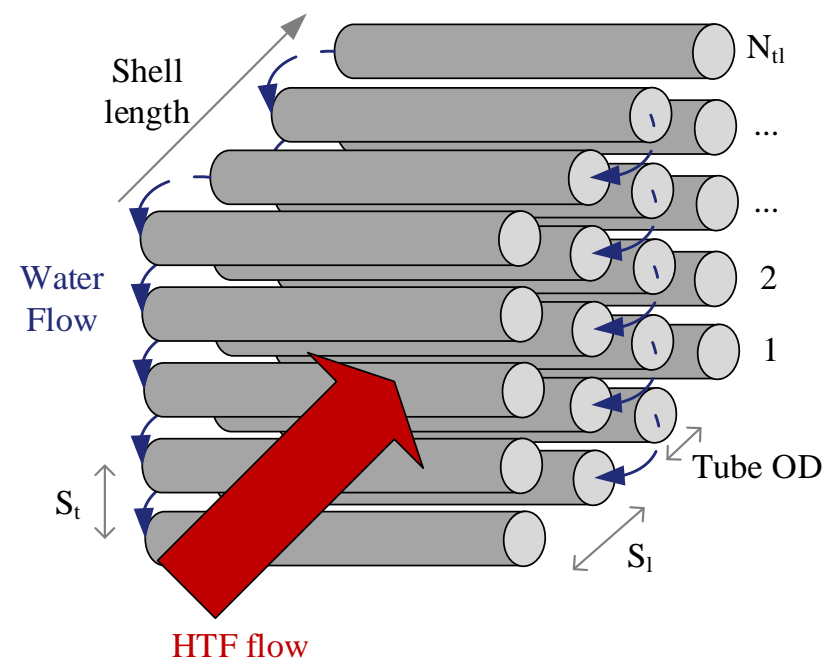

Figure 5: Tube bundle geometry approximation

thermal conductivity $(\lambda)$. In the case of the single phase heat exchangers the tube (water) and the shell (HTF) side heat transfer coefficient were calculated using the Gnielinski [30] and Zukauskas [31] correlations, respectively. In the case of the evaporator, the pool boiling heat transfer coefficient was determined with the Stephan-Abdelsalam correlation [32].

Pressure drops on the shell side were estimated according to the Zukauskas correlation, which takes into account the effective fluid area flow inside the tube layer and is dependent on the number of tube layers the fluid needs to cross [31].

The resulting tube pressure drop can be expressed as the sum of the friction loss on the equivalent length which takes also into account the bend radius and the resulting pressure drop due to the change of direction which is normally expressed in terms of a bend-loss 
coefficient $k_{\mathrm{b}}$. This coefficient depends on the curvature ratio and the bend angle and is obtained according to Idelchik et al. [33]. Equation 5 presents the calculation of the pressure drop where $\rho$ and $u$ are the density and velocity of the fluid, $\theta$ and $R_{\mathrm{b}}$ are the angle and the radius of the bend. Lastly $f_{\mathrm{s}}$ is the Darcy friction factor which was calculated according to the Colebrook equation for the turbulent regime and to the Poiseuille equation for the laminar regime [30].

$$
\Delta P_{f}=\frac{1}{2} f_{\mathrm{D}} \rho u^{2}\left(\frac{\theta R_{\mathrm{b}}}{I D}+L_{\text {tube }}\right)+\frac{1}{2} k_{\mathrm{b}} \rho u^{2}
$$

The driving pressure of the natural circulation mechanism results from the difference in density between the two-phase mixture in the riser and the downcomer tubes [34]. For a given circulation ratio $(\mathrm{CR})$ the resulting tube height $(H)$ is obtained when the driving pressure $(\mathrm{dp})$ equals the frictional and momentum (fm) pressure losses in the natural circulation circuit (downcomer (dc), riser (r) and heat exchangers $(\mathrm{hx})$ ). This was calculated according to Equations 6 and 7. Each pressure drop term is calculated according to Anarratore et al. $[18]$.

$$
\begin{gathered}
\Delta P_{\mathrm{dp}}=g \rho_{\mathrm{dc}} H_{\mathrm{dc}}-g\left(\rho_{\mathrm{hx}} H_{\mathrm{hx}}+\rho_{\mathrm{r}} H_{\mathrm{r}}\right) \\
\Delta P_{\mathrm{fm}}=\Delta P_{\mathrm{dc}}+\Delta P_{\mathrm{r}}+\Delta P_{\mathrm{hx}}+\Delta P_{\text {nozzles }}+\Delta P_{\mathrm{b}}
\end{gathered}
$$

\subsection{Mechanical and geometrical design}

The ASME boiler pressure vessel code (BPVC) provides the norms and regulations for calculating the thickness of the shell, headers and tubes in the heat exchangers, which are made of carbon steel material [35].

The shell diameter of each heat exchanger depends on the geometry of the tube bundle, meaning the number of tube layers and the number of coils of the proposed design. In order to minimize the space required by the shell, the lenght of each coil was calculated to have a square geometry which can be placed inside the shell with a low space waste. Therefore, based on the tube-side geometry the internal diameter was determined and subsequently, according to the BPVC sec. VIII, the thickness of the shell was calculated according to 
Equation 8. The thickness $t$ is dependent on the maximum allowable stress $(S)$ of the chosen material at design temperature, design pressure $p$ (in barg) and a safety coefficient $y$. The equation takes into account a tolerance for allowable corrosion $(C)$ which usually depends on the material and on the fluid as well as on the requirements of the power plant operator.

$$
t_{\text {Shell }}=\frac{p \cdot I D / 2}{S-(1-y) p}+C
$$

A similar approach was adapted for each pipe (like the headers and risers/downcomers) and tube that are included in the geometry of each heat exchanger. The header diameter was calculated in order to align each tube equidistantly in each layer of the tube bundle geometry. Then the thickness was calculated according to Equation 9, which depends on the outer diameter $(O D)$ of the pipes. Equation 10 refers to the tube thickness calculation.

$$
\begin{gathered}
t_{\text {Tubes }}=\frac{p \cdot O D}{S+2 y \cdot p}+C \\
t_{\text {Pipes }}=\frac{p \cdot O D}{2 S+p}+0.005 \cdot O D+C
\end{gathered}
$$

In the case of the evaporator heat exchangers, the tube thickness was not calculated directly, as the highest pressure is on the shell and not on the tube side. For externally loaded tubes the calculation procedure starts by assuming a tube length and thickness, followed by a calculation of the maximum allowable pressure. The iteration stops when this value is higher than or equal to the design pressure considered.

The steam drum volume depends on the operating pressure and on the steam load required by the evaporator. The steam volume chamber was determined according to charts that illustrates the minimum and maximum steam volumes as a function of the operating pressure according to Anarratore et al [18]. The volume was determined to ensure that the maximum vapor velocity that allows gravitational settling of entrained liquid is not exceeded [18]. Considering that usually the water level corresponds with the center line of the drum, the drum volume becomes twice as large as the required steam drum chamber. According to industrial experience, the internal drum diameter was set to a minimum value of $1.5 \mathrm{~m}$ in order to allow for the correct placement of the separating devices and space requirement 
for internal inspection.

\subsection{Heating rates calculations}

The maximum allowable heating rates $\left(v_{\mathrm{T}}\right)$ were determined according to the European standard EN 12952-3, in order to keep the resulting stress in the singularities (i.e. junction between downcomer and steam drum or header and tubes) below the allowable stress $\left(\sigma_{\mathrm{a}}\right)$ determined from a LCF diagram for a given number of cycles corresponding to the chosen lifetime of the component [12]. Equation 11 summarizes the concept and illustrates how the resulting total stress is a sum of the thermal stress and tensile stress. They depend on a thermal and mechanical stress concentration factors respectively $(\alpha)$, which were calculated according to the norm. $E, \beta, \nu$ are the Young's modulus, thermal expansion coefficient and Poisson's ratio, respectively. The main non-dimentional parameter is $\Phi_{\mathrm{w}}$ which depends on the outer to inner diameter ratio $\omega$ according to Equation 12.

$$
\begin{gathered}
\left|\alpha_{\mathrm{m}}\left(p-p_{0}\right) \frac{I D+t}{t}+\alpha_{\mathrm{T}} \cdot c \cdot \rho \frac{E \cdot \beta}{1-\nu} \frac{v_{\mathrm{T}} t^{2}}{\lambda} \Phi_{\mathrm{w}}\right| \leq\left|\sigma_{\mathrm{a}}\right| \\
\Phi_{\mathrm{w}}=\frac{1}{8} \frac{\left(\omega^{2}-1\right)\left(3 \omega^{2}-1\right)-4 \omega^{4} \cdot \ln \omega}{\left(\omega^{2}-1\right)(\omega-1)^{2}}
\end{gathered}
$$

The norm provides the allowable rates at the corresponding minimum and maximum pressure $p_{1}, p_{2}$ in the specified start-up cycle. Once the two values are determined the heating rate can be calculated at each intermediate pressure by means of linear interpolation according to Equation 13. In case of two-phase conditions the pressure $\mathrm{p}(\mathrm{t})$ becomes function of the fluid temperature $T_{\mathrm{f}}$, therefore the equation was solved using a fourth-order RungeKutta method [36]. Otherwise, the pressure is function of time and the equation can be directly solved [7]. The minimum and maximum heating rates do not however illustrate the overall start-up process as $v_{\mathrm{T}}$ changes during the start-up phase. In order to capture the overall responsiveness of the start-up procedure an average heating rate was defined according to Equation 14. The heating rates were also calculated for a specific start-up cycle, which was obtained from the results of a parabolic trough model, previously developed by the authors [6]. The chosen lifetime equals to 25 years, with 346 starts in a year of which 91 hot, 234 warm and 21 cold starts which would respectively correspond to starting pressure of 26 bar, 16 bar and 1 bar, respectively. 


$$
\begin{gathered}
\frac{d T_{\mathrm{f}}}{d t}=\frac{p_{2} \cdot v_{\mathrm{T} 1}-p_{1} \cdot v_{\mathrm{T} 2}}{p_{2}-p_{1}}+\frac{v_{\mathrm{T} 2}-v_{\mathrm{T} 1}}{p_{2}-p_{1}} \cdot p(t) \\
v_{\text {Taverage }}=\frac{1}{t_{\text {end }}-t_{\text {start }}} \cdot \int_{t_{\text {start }}}^{t_{\text {end }}} \frac{d T_{\mathrm{f}}}{d t} \mathrm{~d} t
\end{gathered}
$$

\subsection{Cost estimation}

The cost estimation of the whole SGS was carried out following the methodology presented by Purohit et al. [21]. The methodology is based on estimating the cost of a baseline exchanger according to Equation 15, where $p_{\mathrm{OD}}, f$ and $r$ are cost multipliers for the outer diameter, front and rear head types, respectively. The total heat exchange cost was then determined as a function of the heat exchange area according to Equation 17, where $N_{\mathrm{s}}$ represents the number of shells and $c_{\mathrm{i}, \mathrm{j}}$ represent a number of correction factors which take into account design pressure, length of the tubes and material selection. The cost of the steam drum was estimated as a function of the drum metal mass [37] and carbon steel prices according to Ref. [38]. Lastly the total investment cost was adjusted to 2017 as a reference year according to the historical price index (HPI) reported in Ref. [39].

$$
\begin{gathered}
b=\left(\frac{6.6}{1-e^{\left(\frac{7-I D}{27}\right)}}\right) \cdot p_{\mathrm{OD}} \cdot f \cdot r \\
P E C_{\mathrm{hx}}=b \cdot\left(1+\sum_{i=1}^{n} c_{\mathrm{i}}\right) \cdot A \cdot N_{\mathrm{s}} \\
P E C_{\mathrm{SGS}}=\frac{H P I_{2017}}{H P I_{1983}} \cdot \sum_{\mathrm{j}=1}^{n_{\mathrm{hx}}}\left(b_{\mathrm{j}} \cdot\left(1+\sum_{\mathrm{i}=1}^{\mathrm{n}} c_{\mathrm{i}, \mathrm{j}}\right) \cdot A_{\mathrm{j}} \cdot N_{\mathrm{s}, \mathrm{j}}\right)
\end{gathered}
$$

\subsection{Optimization and constraints}

Apart from the investment cost, another important parameter to consider during a heat exchanger feasibility study is the pressure drop of both fluids. The lower the pressure drop, the higher the heat exchanger area required as lower heat transfer coefficients are obtained. 
Therefore investment cost and pressure drops are conflicting parameters. Moreover, from a system perspective, higher mass flow rates from the HTF side would imply higher parasitic consumptions and therefore lower profitability of the power plant. Lastly, if the CSP plant includes TES systems, lower outlet HTF temperatures would allow for a lower cost on the thermal energy storage. Gonzalez-Gomez et al. [25] included all these consideration in their cost analysis, however, as the focus of this paper is to look into the details of just the SGS, only the minimization of the pressure drop and PEC was considered. Secondly it is common practice in industry to ask the manufacturer of SGSs for a system of heat exchangers for certain fixed power plant specifications and maximum allowable pressure drop. Hence having a trade-off curve between pressure drop and PEC, would allow to choose the most cost effective design for a set of power plant constraints.

The optimization was carried with the genetic algorithm multi-objective optimization toolbox available in Matlab by varying the parameters as presented in Table 2. It was decided to choose the same tube outer diameter for each heat exchanger, to favour an economy of scale. The diameter was chosen to be a discrete variable, with the possibility to choose from four different commonly available tube outer diameters according to Coulson et al. [40]. The four choices (refered as index in Table 3) were $25 \mathrm{~mm}, 30 \mathrm{~mm}, 38 \mathrm{~mm}$ and $50 \mathrm{~mm}$, respectively, with lower diameters excluded from the optimization since these designs gave rise to high pressure drops (above 10 bar). The tube pitch values, were chosen to be fixed to the lowest value allowable by not drastically increasing the pressure drops. This resulted in a tube pitch ratio (distance/diameter) of 1.25 and a staggered alignment to allow for the lowest shell diameters, higher heat transfer coefficient and easy mechanical cleaning $[17,41]$. These choices are also in agreement with to the results presented by Gonzalez-Gomez et al. [25].

In order to allow the optimization algorithm to obtain feasible designs, constraints were set according to Table 3 . The minimum and maximum tube side velocities were set in order to reduce possible fouling and avoid excessive corrosion, respectively [40]. The maximum steam flow velocities were set according to the steam velocity diagram which are dependent on operational pressure, presented by Merritt et al. [42].

The constraints also took into consideration the minimum heating rates for each component (header/tube junction for single phase heat exchangers and drum/downcomer juction for the evaporator). As the evaporator is the main limiting component for the SGS, a minimum heating rate was chosen according to a previous work by the authors [6]. This values was chosen to maximize the electric power output of the power plant. All the other com- 
Table 2: Optimization decision variables

\begin{tabular}{lccc}
\hline Variables & Unit & Lower boundary & Upper boundary \\
\hline Tube outer diameter index & {$[-]$} & 1 & 4 \\
RHe number of layers & {$[-]$} & 20 & 40 \\
RHs number of layers & {$[-]$} & 20 & 40 \\
EVA number of layers & {$[-]$} & 20 & 40 \\
SUP number of layers & {$[-]$} & 20 & 40 \\
ECO number of layers & {$[-]$} & 20 & 40 \\
Rhe number of tubes per layer & {$[-]$} & 3 & 15 \\
RHs number of tubes per layer & {$[-]$} & 3 & 15 \\
EVA number of tubes per layer & {$[-]$} & 3 & 15 \\
SUP number of tubes per layer & {$[-]$} & 3 & 15 \\
ECO number of tubes per layer & {$[-]$} & 3 & 15 \\
Riser outer diameter & {$[\mathrm{mm}]$} & 200 & 300 \\
Number of risers & {$[-]$} & 5 & 15 \\
\hline
\end{tabular}

ponents were checked to have a lifetime higher than or equal to 25 years. The optimization was carried for the following two cases:

1. No LCF constraints

2. LCF constraints, with minimum heating rate for both the evaporator and super-heater

Table 3: Optimization constraints

\begin{tabular}{lll}
\hline Parameter & Unit & Value \\
\hline Tube minimum velocity & {$[\mathrm{m} / \mathrm{s}]$} & 0.5 \\
Tube maximum velocity & {$[\mathrm{m} / \mathrm{s}]$} & 4 \\
Shell minimum velocity & {$[\mathrm{m} / \mathrm{s}]$} & 0.2 \\
Shell maximum velocity & {$[\mathrm{m} / \mathrm{s}]$} & 1.5 \\
Steam maximum velocity & {$[\mathrm{m} / \mathrm{s}]$} & 25 \\
Oil maximum pressure drop & {$[\mathrm{bar}]$} & 2 \\
Evaporator minimum heating rate & {$[\mathrm{K} / \mathrm{min}]$} & 8.5 \\
Super-heater minimum heating rate & {$[\mathrm{K} / \mathrm{min}]$} & 15 \\
Minimum drum internal diameter & {$[\mathrm{mm}]$} & 1500 \\
\hline
\end{tabular}

Other constraints, which specifically apply only for the evaporator, were related to limiting the maximum heat flux for the tube bundle to avoid film boiling [43, 44] and assuring that the critical flow $G_{\mathrm{c}}$ in the water-steam mixture is not reached. This was estimated 
according to Equation 18, in which the reference (ref) properties were calculated at the upstream stagnation point (steam drum) and $c_{\mathrm{f}}$ is a choking correction factor [45].

$$
G_{\mathrm{c}}=\sqrt{2 \cdot\left[p_{\mathrm{ref}}-c_{\mathrm{f}} \cdot p_{\mathrm{sat}} \cdot\left(T_{\mathrm{ref}}\right)\right] \cdot \rho_{\mathrm{l}, \mathrm{ref}}}
$$




\section{Results and discussion}

\subsection{Model validation}

A steady state validation was performed by comparing the most significant outputs of the model with data of the SGS of an existing 55 MWe parabolic trough power plant. Table 4 summarizes the validation of the key parameters of the design routine. As the detailed geometrical design of the components considered for evaluating the accuracy of the model is confidential, only the main results are presented here. The total area required by each heat exchanger is in line with the plant data with a deviation of $+2.5 \%$, meaning that the model is able to predict the heat transfer coefficients with a reasonable degree of accuracy. This is also reflected in a deviation below $1 \%$ for the total HTF temperature drop. The small deviations in outlet velocities of water and HTF indicate that the pressure drop on each fluid side are estimated with good accuracy. The total cost figure as well as the detailed geometrical parameters are confidential information and can therefore not be presented. Instead a comparison of the weight of the components is presented, since the weight can be considered as a direct indicator of the cost of the heat exchangers. The table indicates that even though the area is overestimated, the weight experiences an opposite trend. This can be explained by the fact that the thicknesses of the components are underestimated with an average of $2.9 \%$. In conclusion, the results of the validation suggest that the models provide sufficiently accurate results for the purpose of work presented in this paper.

Table 4: Validation results

\begin{tabular}{llccc}
\hline Parameters & Units & Model & Plant data & Deviation \\
\hline Total area required (HTF side) & {$\left[\mathrm{m}^{2}\right]$} & 2755 & 2688 & $2.50 \%$ \\
HTF SGS temperature drop & {$[\mathrm{K}]$} & 92.40 & 91.70 & $0.76 \%$ \\
Pressure drop (HTF side) & {$[\mathrm{bar}]$} & 1.663 & 1.640 & $1.40 \%$ \\
Pressure drop (Water side) & {$[\mathrm{bar}]$} & 1.850 & 1.852 & $-0.11 \%$ \\
Velocity SH steam outlet & {$[\mathrm{m} / \mathrm{s}]$} & 10.81 & 10.95 & $-1.32 \%$ \\
Velocity ECO HTF outlet & {$[\mathrm{m} / \mathrm{s}]$} & 0.912 & 0.900 & $1.33 \%$ \\
EVA maximum heating rate & {$[\mathrm{K} / \mathrm{min}]$} & 8.830 & 9.000 & $-1.89 \%$ \\
Total weight & {$[\mathrm{ton}]$} & 231.8 & 240.4 & $-3.59 \%$ \\
\hline
\end{tabular}

\subsection{Optimization results}

The multi-objective optimization results are presented in Figure 6. Figure 6a presents a comparison of the results when excluding (Case 1) and including the LCF constraints 
(Case 2), see Section 2.6. Figure 6b presents the optimization results with the HTF total pressure drop as color. If the main thermodynamic constraints are considered (Case 1), the $25 \mathrm{~mm}$ outer diameter solution is excluded as the pressured drop and velocity constraints (HTF/water) are not met. Therefore only the other three diameters $30 \mathrm{~mm}, 38 \mathrm{~mm}$ and $50 \mathrm{~mm}$ (from left to right) are feasible tube diameter options. If the LCF constraints are considered with a required minimum heating rate for the evaporator (Case 2), the $30 \mathrm{~mm}$ outer diameter is excluded for two reasons. In the case of low tube number (towards the lower limit), the pressure drop on the SH side would increase significantly, meaning higher steam pressure requirement at the drum, if the turbine inlet pressure constant is considered to be constant. This would require higher thicknesses on both the drum and downcomer tubes, increasing thermal stresses and lowering the maximum allowable heating rates. If the superheater tube number would be increased the header diameter would need to be increased. This would mean higher thickness requirements, therefore the superheater header would experience higher thermal stresses, hence the LCF constraints would not be satisfied at the superheater tube/header junction.

If a tube diameter of $50 \mathrm{~mm}$ for all the heat exchangers is considered, for the same pressure drop the design would change with an associated increase in PEC. For instance for 0.1 bar pressure drop this would result in a $7.6 \%$ increase in the PEC. This is due to the fact that in order to keep low pressure drops as well as meeting the LCF constraints, more layers would be required resulting in higher shell diameters. This would in turn increase the cost for the superheater.

Figure 6a also illustrates that in order to obtain a desired pressure drop, the design could drastically change if the LCF constraints are considered during the design procedure. For instance, if a 1 bar pressure drop is required, the PEC would increase by around 0.75 milion USD. Even though this figure corresponds to a $42 \%$ increase in capital cost of the SGS, it is justifiable if the economy of the whole power plant is taken into consideration. According to a previous work of the authors [6], an evaporator $v_{\mathrm{T}}$ increase from $3 \mathrm{~K} / \mathrm{min}$ to $8.5 \mathrm{~K} / \mathrm{min}$ would imply an increase in electricity production which would range between $1.5 \%$ and 5 $\%$, depending if the superheater is optimally designed and operated considering the heating rate perspective. In a 25 years lifetime of the plant, and even assuming the lowest bid for CSP power production of $94.5 \mathrm{USD} / \mathrm{MWh}$ [46], this would result in an increase in revenues between 2.1 milion USD and 7.1 milion USD.

The optimal geometrical parameters for Case 2 for different conditions are presented in Table 5. It lists the aritmetic mean average, relative standard deviation (RSD) around the 


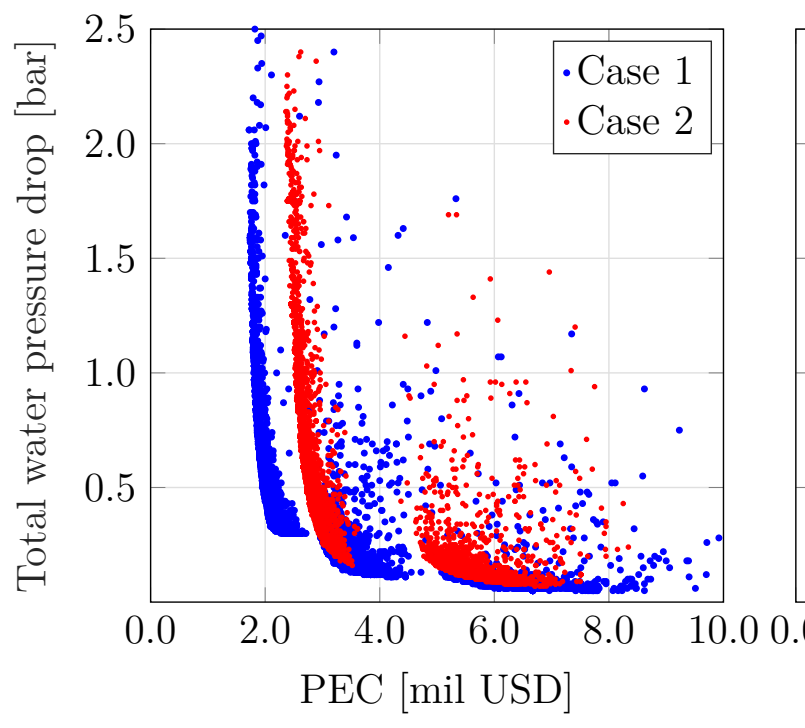

(a) Comparison between the three cases

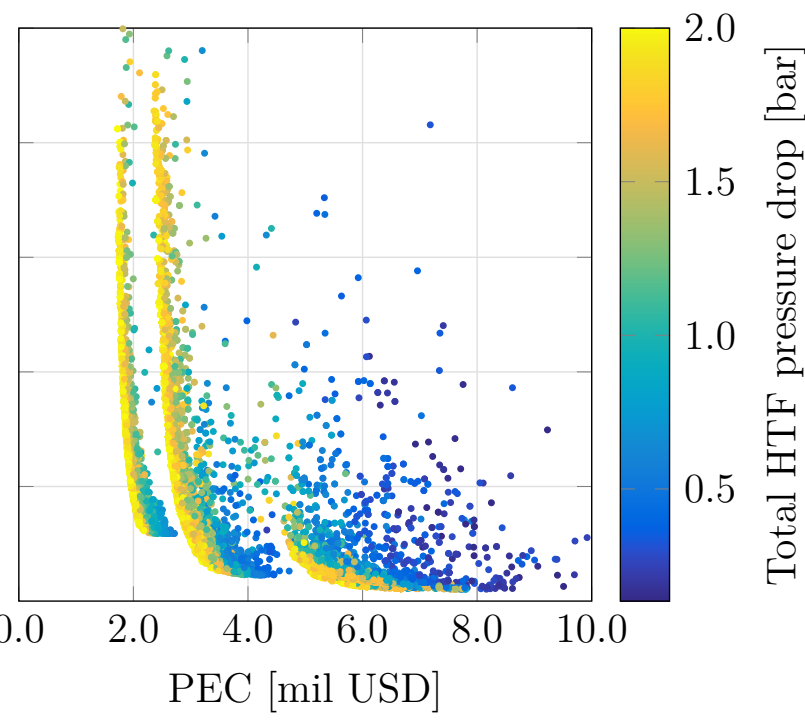

(b) HTF total pressure drop

Figure 6: Optimization results

mean and minimum and maximum values of the optimized variables at the Pareto front. In order to give an indication of feasible designs for different pressure drops, the table is split between pressure drops higher and lower than 1 bar for the solution corresponding to a tube outer diameter of $38 \mathrm{~mm}$. A third column is presented for the $50 \mathrm{~mm}$ solution, which corresponds to pressure drops lower than 0.225 bar. A low RSD and small difference between minimum and maximum values mean that the correspondent variable does not vary significantly within the optimal configuration. The EVA, ECO, SH number of layers and EVA tubes per layer present the lowest RSD for pressure drops higher than 1 bar. Similar conclusion can be drawn for designs which would result in lower pressure drops. The results presented for the number of tube layers for the superheater support the aforementioned discussion regarding the necessity to increase such parameter in case low pressure drops are required. The third column shows that in this case an increase by $28 \%$ is necessary to satisfy this condition.

It may also be noticed that the riser configuration (outer diameter and numbers) presents a low RSD. Low number of risers would imply higher pressure drops, therefore larger height values for both downcomers and risers. Larger diameters would imply lower velocities, hence lower pressure drops, but higher required thicknesses. The results presented in the three columns can be interpreted as the optimal configuration, considering the trade-off between the number of tubes and diameter to minimize thickness and height, hence the 
associated cost. The differences among the three columns are due to the different operating pressure at the evaporator (due to higher pressure drops at the super-heater), hence different optimal configurations. Table 6 illustrates the results of the optimized geometry for a 1 bar pressure drop on the water side. The header diameter results support the aforementioned observations concerning the number of tubes. Low numbers are preferred in the high pressure heat exchangers, while large header diameters are preferred on the re-heater train side. The two most expensive components are the evaporator and superheater, accounting for $34 \%$ and $27 \%$, respectively, of the overall PEC. That is also why the optimizer tends to a low number of tubes and high heat transfer coefficients for these components. On the other hand, the re-heaters are less sensitive both from a heating rate and area/cost perspectives, accounting for $14 \%$ and $12 \%$ of the overall PEC. That is why in Table 5, the re-heater parameters experience high variations in the optimal solutions.

In order to minimize the PEC, the HTF total pressure drop converges to the maximum allowable value of 2 bar. That is, if this value decreases, higher costs would be obtained, see Figure $6 \mathrm{~b}$. This is mainly due to the fact that, in order to decrease the shell side velocity, a lower number of coils would be needed, meaning higher number of tubes. In turn this would cause low water side velocities hence an increased heat exchanger area requirement. This would mean that for a water-side 1 bar pressure drop, decreasing the HTF pressure drop from 2.0 to 1.5 bar would result in a PEC increase of $13 \%$.

It needs to be stressed that the results presented in this section are governed by the power plant design specifications. Therefore, if a CSP plant is optimized while employing the method presented in this paper for the SGS design, different optimal SGS designs than the ones presented here may be obtained, depending on the size of the solar field and thermal energy storage. However, the method presented in this paper can be used to provide guidelines on how to design the SGS for a given set of design specifications. 
Table 5: Optimization results for Case 2. Minimum, mean, maximum and relative standard deviation of the optimized variables. The values are acquired from the Pareto front in Figure 6a.

\begin{tabular}{|c|c|c|c|c|c|c|c|c|c|c|c|c|c|}
\hline \multirow[b]{2}{*}{ Variables } & \multirow[b]{2}{*}{ Units } & \multicolumn{4}{|c|}{ Higher than 1 bar } & \multicolumn{4}{|c|}{ Between 0.225 and 1 bar } & \multicolumn{4}{|c|}{ Lower or equal to 0.225 bar } \\
\hline & & $\min$ & mean & $\max$ & $\mathrm{RSD}$ & $\min$ & mean & $\max$ & RSD & $\min$ & mean & $\max$ & RSD \\
\hline Tube outer diameter & {$[\mathrm{mm}]$} & 38 & 38 & 38 & $0 \%$ & 38 & 38 & 38 & $0 \%$ & 50 & 50 & 50 & $0 \%$ \\
\hline RHe number of layers & {$[-]$} & 28 & 29 & 30 & $3 \%$ & 28 & 32 & 39 & $10 \%$ & 27 & 34 & 38 & $9 \%$ \\
\hline RHs number of layers & {$[-]$} & 31 & 34 & 36 & $5 \%$ & 34 & 35 & 35 & $1 \%$ & 28 & 34 & 40 & $8 \%$ \\
\hline EVA number of layers & {$[-]$} & 29 & 30 & 33 & $4 \%$ & 21 & 23 & 29 & $7 \%$ & 20 & 20 & 22 & $3 \%$ \\
\hline SH number of layers & {$[-]$} & 20 & 22 & 24 & $6 \%$ & 21 & 25 & 29 & $6 \%$ & 25 & 32 & 39 & $13 \%$ \\
\hline ECO number of layers & {$[-]$} & 21 & 23 & 26 & $6 \%$ & 21 & 22 & 29 & $6 \%$ & 20 & 21 & 29 & $9 \%$ \\
\hline RHe number of tubes per layer & {$[-]$} & 7 & 8 & 10 & $14 \%$ & 8 & 11 & 13 & $10 \%$ & 14 & 15 & 15 & $3 \%$ \\
\hline RHs number of tubes per layer & {$[-]$} & 7 & 8 & 9 & $11 \%$ & 8 & 11 & 15 & $18 \%$ & 14 & 15 & 15 & $3 \%$ \\
\hline EVA number of tubes per layer & {$[-]$} & 4 & 4 & 4 & $0 \%$ & 4 & 5 & 5 & $4 \%$ & 3 & 3 & 5 & $21 \%$ \\
\hline SH number of tubes per layer & {$[-]$} & 4 & 6 & 7 & $18 \%$ & 7 & 10 & 11 & $10 \%$ & 8 & 8 & 11 & $12 \%$ \\
\hline ECO number of tubes per layer & {$[-]$} & 5 & 6 & 7 & $12 \%$ & 5 & 6 & 8 & $13 \%$ & 6 & 7 & 8 & $9 \%$ \\
\hline Riser outer diameter & {$[\mathrm{mm}]$} & 253 & 280 & 296 & $5 \%$ & 261 & 293 & 300 & $3 \%$ & 294 & 298 & 300 & $1 \%$ \\
\hline Number of risers & {$[-]$} & 5 & 6 & 7 & $10 \%$ & 5 & 6 & 8 & $9 \%$ & 5 & 6 & 8 & $8 \%$ \\
\hline
\end{tabular}

Table 6: Result design for 1 bar pressure drop on water side

\begin{tabular}{llllllll}
\hline Parameter & Units & ECO & \multicolumn{2}{c}{ EVA $(\dagger)$} & SH & RHe & RHs \\
\hline Shell diameter & {$[\mathrm{mm}]$} & 1636 & 1465 & 1658 & 1709 & 2246 & 2599 \\
Shell length & {$[\mathrm{mm}]$} & 9.3 & 13.2 & 8.95 & 15.03 & 16.54 & 17.1 \\
Shell thickness & {$[\mathrm{mm}]$} & 18 & 65 & 79 & 20 & 23 & 29 \\
Number of shells & {$[-]$} & 1 & 2 & 1 & 1 & 1 & 1 \\
Tube outer diameter & {$[\mathrm{mm}]$} & 38 & 38 & 38 & 38 & 38 \\
Tube thickness & {$[\mathrm{mm}]$} & 3.8 & 4.8 & 3.8 & 3.8 & 3.8 \\
Tube layers & {$[-]$} & 22 & 29 & 23 & 30 & 34 \\
Tube per layers & {$[-]$} & 6 & 4 & 7 & 9 & 9 \\
Tube coils & {$[-]$} & 23 & 3 & 34 & 10 & 12 \\
Header diameter & {$[\mathrm{mm}]$} & 380.6 & 216.4 & 465.9 & 560.5 & 489.2 \\
Header thickness & {$[\mathrm{mm}]$} & 27.0 & 22.6 & 37.0 & 19.0 & 16.0 \\
Tube side average flow velocity & {$[\mathrm{m} / \mathrm{s}]$} & 0.52 & 3.39 & 6.50 & 18.48 & 17.82 \\
Shell side average flow velocity & {$[\mathrm{m} / \mathrm{s}]$} & 1.01 & - & 1.04 & 0.59 & 0.52 \\
Tube side heat transfer coefficient & {$\left[\mathrm{W} /\left(\mathrm{m}^{2} \mathrm{~K}\right)\right]$} & 4567.0 & 5311.0 & 2024.3 & 735.5 & 578.3 \\
Shell side heat transfer coefficient & {$\left[\mathrm{W} /\left(\mathrm{m}^{2} \mathrm{~K}\right)\right]$} & 1993.1 & 23472.7 & 1866.1 & 1441.3 & 1218.1 \\
Overall heat transfer coefficient & {$\left[\mathrm{W} /\left(\mathrm{m}^{2} \mathrm{~K}\right)\right]$} & 1155.2 & 3245.6 & 1155.2 & 402.7 & 325.4 \\
Oil side pressure drop & {$[\mathrm{bar}]$} & 0.289 & 1.133 & 0.445 & 0.078 & 0.294 \\
Water side pressure drop & {$[\mathrm{bar}]$} & 0.031 & 0.017 & 0.472 & 0.294 & 0.206 \\
CAPEX & {$[\mathrm{mil} \mathrm{USD}]$} & 0.350 & 0.850 & 0.690 & 0.290 & 0.350 \\
$v_{\text {T }}$ average & {$\left[\mathrm{K} / \mathrm{min}^{2}\right]$} & 68.7 & 9.1 & 31.7 & 246.1 & 153.7 \\
\hline
\end{tabular}

(†) The shell parameters refer to the heat exchangers (on the left) and steam drum (on the right). 


\section{Conclusions}

A design tool was developed to size all the heat exchangers of a steam generator system for concentrating solar power applications. The models included the area calculations based on heat transfer coefficients, sizing of the main components, such as tubes, headers and shells and evaluation of low cycle fatigue requirements, in terms of maximum allowable heating rates for the most sensible components. The sizing was also coupled with a cost estimation model. This allows to couple the thermo-mechanical and economic aspect to integrate the model in a genetic algorithm based multi-objective optimization to minimize both pressure drops and purchase equipment cost.

The results of the validation indicate that models provide accurate results, resulting in an overestimation of the total heat exchanger area by $2.5 \%$ compared to components installed in existing power plants. The total weight was underestimated by $3.6 \%$. Lastly the LCF norms were implemented with a resulting deviation in evaporator heating rate calculation of $-1.9 \%$ compared to that of the existing power plant.

The results of the multi-objective optimization indicate that integrating the LCF analysis in the design routine of steam generator systems can change significantly the design of the heat exchangers. If both super-heater and evaporator minimum heating rates constraints are considered, only two tube outer diameter choices $(38 \mathrm{~mm}, 50 \mathrm{~mm}$ ) give a optimal solutions. If 1 bar water-side pressure drop is a requirement from a power plant owner, the cost of an optimal heat exchanger could potentially increase by 0.75 mil USD (42\% purchase equipment cost increase). However, considering that high heating rates could lead to increase in electricity production, the increase in SGS cost can be justifiable. The optimization results also suggest that a lower HTF total pressure drop constraint implies high purchase equipment costs. Specifically, for the 1 bar water side pressure drop design, lowering the HTF pressure drop from 2.0 bar to 1.5 bar would imply a PEC increase of $13 \%$.

The results presented in this work are specifically tailored for one power plant design in order to keep the focus of the work only on the component design. Integrating this methodology in a more general system level optimization may lead to different steam generator optimal configurations depending on the power plant specifications, such as thermal energy storage, solar field size and parasitic consumption. 


\section{References}

[1] International Energy Agency. Technology Roadmap, Solar Thermal Electricity. Technical report, IEA, Paris, France, 2014.

[2] Thomas R. Mancini, Jesse A. Gary, Gregory J. Kolb, and Clifford Kuofei Ho. Power Tower Technology Roadmap and cost reduction plan. Sandia Report. Technical Report Sandia Report, April, Sandia, Sandia National Laboratories. Albuquerque, New Mexico, 2011.

[3] World Energy Council. World Energy Resources: Solar 2016. Technical report, London, England, 2016.

[4] Groupe Reaction Inc. CSP Parabolic Trough Report : Cost, Performance and Key Trends. Technical report, CSP Today, London, England, 2014.

[5] Estela, Greenpeace, and Solarpaces. Solar Thermal Electricity - Global Outlook 2016. Technical report, Brussels, Belgium, 2016.

[6] D. Ferruzza, M. Topel, B. Laumert, and F. Haglind. Impact of steam generator start-up limitations on the performance of a parabolic trough solar power plant. Solar Energy, 169:255-263, 2018.

[7] Piotr Dzierwa and Jan Taler. Optimum Heating of Pressure Vessels With Holes. Journal of Pressure Vessel Technology, 137(1):011202, 2014.

[8] Piotr Dzierwa, Dawid Taler, Marcin Trojan, and Jan Taler. Evaporator Heating with Optimum Fluid Temperature Changes. Procedia Engineering, 157:29-37, 2016.

[9] Jan Taler, Bohdan Weglowski, Dawid Taler, Tomasz Sobota, Piotr Dzierwa, Marcin Trojan, Paweł Madejski, and Marcin Pilarczyk. Determination of start-up curves for a boiler with natural circulation based on the analysis of stress distribution in critical pressure components. Energy, 92:153-159, 2015.

[10] P A Gonzalez-Gomez, J Gomez-Hernandez, J V Briongos, and D Santana. Fatigue analysis of the steam generator of a parabolic trough solar power plant. Energy, 155:565-577, 2018.

[11] Piotr Duda and Dariusz Rzasa. Numerical method for determining the allowable medium temperature during the heating operation of a thick-walled boiler element in a supercritical steam power plant. International Journal of Energy Research, 36(6):703-709, 2012.

[12] CEN. Water-tube boilers and auxiliary installations - Part 3: Design and calculation for pressure parts of the boiler. Technical report, European Committee for Standardization, Brussels, Belgium, 2012.

[13] L. L. Vant-Hull. Central tower concentrating solar power (CSP) systems. Woodhead Publishing Limited, Houston, Texas, 2012.

[14] Leonardo Pelagotti, Kim Sørensen, Thomas J Condra, Thomas Joseph, and Alessandro Franco. Modelling of a Coil Steam Generator for CSP applications. In Proceedings of the 55th International Conference on Simulation and Modelling, 2014.

[15] M. Serna and Arturo Jiménez. A compact formulation of the Bell-Delaware method for heat exchanger design and optimization. Chemical Engineering Research and Design, 83(5 A):539-550, 2005.

[16] Robert W. Serth and Thomas G. Lestina. The Stream Analysis Method. Academic Press, Boston, Massachusetts, second edition edition, 2014.

[17] D. Q. Kern. Process Heat Transfer. McGraw-Hill, Singapore, 1965.

[18] Donatello Anarratore. Steam generators. Description and design. Springer, Milano, Italy, 2008.

[19] Donatello Anarratore. Handbook for heat exchangers and tube banks design. Springer, Milano, Italy, 2010.

[20] S. G. Hall, S. Ahmad, and R. Smith. Capital cost targets for heat exchanger networks comprising mixed 
materials of construction, pressure ratings and exchanger types. Computers and Chemical Engineering, 14(3):319-335, 1990.

[21] G. P. Purohit. Estimating costs of shell-and-tube heat exchangers. Chemical Engineering, (90):56-67, 1983.

[22] M $M^{\mathrm{a}}$. Dolores Durán, Manuel Valdés, Antonio Rovira, and E. Rincón. A methodology for the geometric design of heat recovery steam generators applying genetic algorithms. Applied Thermal Engineering, 52(1):77-83, 2013.

[23] Alessandro Franco and Nicola Giannini. A general method for the optimum design of heat recovery steam generators. Energy, 31(15):3342-3361, 2006.

[24] Philippe Wildi-Tremblay and Louis Gosselin. Minimizing shell-and-tube heat exchanger cost with genetic algorithms and considering maintenance. International journal of energy research, 31(31):135-147, 2007.

[25] P.A. González-Gómez, F. Petrakopoulou, J.V. Briongos, and D. Santana. Cost-based design optimization of the heat exchangers in a parabolic trough power plant. Energy, 123:314-325, 2017.

[26] MATLAB. version 9.1.0.4 (R2016b). The MathWorks Inc., Natick, Massachusetts, 2016.

[27] Geoffrey Basil Leyland and Daniel Favrat. Multi-objective optimization applied to industrial energy problems. PhD thesis, École Polytechnique Féderale de Lausanne, (EPFL), Lausanne, 2002.

[28] NREL. System Advisor Model (SAM) Case Study: Andasol. Technical report, NREL, Aldeire, Spain, 2013.

[29] Aalborg CSP. http://www.aalborgcsp.com/quickmenu/brochures/. [accessed: 2017-08-03].

[30] Theodore Bergman, Adrienne Lavine, Frank Incropera, and David Dewitt. Fundamentals of heat and mass transfer. John Wiley and sons, Jefferson city, Missouri, 7th edition, 2011.

[31] A. Žukauskas. Heat transfer from tubes in crossflow. Advances in Heat Transfer, 8:93-160, 1972.

[32] K. Stephan and M. Abdelsalam. Heat-transfer correlations for natural convection boiling. International Journal of Heat and Mass Transfer, 23(1):73-87, 1980.

[33] I.E. Idelchik. Hanbook of hydraulic resistance. Coefficients of Local Resistance and of Friction. National Science Foundation, Jerusalem, Israel, 1986.

[34] V. Ganapathy. Understanding boiler circulation. Chemical Engineering, 120(10):52-56, 2013.

[35] American society of mechanical engineer. ASME Boiler and Pressure Vessel Code: Section VIII Division 2. New York, New York, 2015.

[36] J.C. Butcher and G. Wanner. Runge-kutta methods: some historical notes. Applied Numerical Mathematics, 22(1):113 - 151, 1996. Special Issue Celebrating the Centenary of Runge-Kutta Methods.

[37] J. D. Seader, Warren D. Seider, and Daniel R. Lewin. Product and Process Design Principles: Synthesis, Analysis and Evaluation. Wiley, USA, 2004.

[38] MEPS International. http://worldsteelprices.com/. [accessed: 01/03/2018].

[39] Capital professional services. https://inflationdata.com/. [accessed: 01/03/2018].

[40] Gavin Towler and Ray Sinnott. Heat-Transfer Equipment. In Chemical Engineering Design, pages 1047-1205. Oxford, England, 2013.

[41] Waqar Ahmed Khan, M. M. Yovanovich, and J. R. Culham. Optimal design of tube banks in crossflow using entropy generation minimization method. Journal of thermophysiscs and heat transfer, $21(2): 372-378,2007$. 
[42] Carey Merritt. Process Steam Systems: A Practical Guide for Operators, Maintainers, and Designers. John Wiley \& Sons, New Jersey, 2015.

[43] J. W. Palen. Shell and tube reboilers. In Heat exchanger design handbook. Begell House, London, England, 2002.

[44] S.G. Kandlikar. A theoretical model to predict pool boiling critical heat flux incorporating effects of contact angle and orientation. ASME Journal of Heat Transfer, 123(6):1071-1079, 2001.

[45] Yeon Sik Kim. A proposed correlation for critical flow rate of water flow. Nuclear Engineering and Technology, 47(1):135-138, 2015.

[46] New energy update. http://analysis.newenergyupdate.com/csp-today/acwa-power-scales-tower-troughdesign-set-record-low-csp-price. [accessed: 02/07/2018]. 